\title{
Adverse events in older patients undergoing colonoscopy: a systematic review and meta-analysis
}

\author{
Lukejohn W. Day, MD ${ }^{1,2}$, Annette Kwon, MD $^{3}$, John M. Inadomi, MD ${ }^{4}$, Louise C. Walter, \\ MD $^{5}$, and Ma Somsouk, MD, MAS ${ }^{1,2}$ \\ San Francisco, California, Seattle, Washington, USA
}

\begin{abstract}
Background-Studies suggest that advancing age is an independent risk factor for experiencing adverse events during colonoscopy. Yet many of these studies are limited by small sample sizes and/or marked variation in reported outcomes.
\end{abstract}

Objective-To determine the incidence rates for specific adverse events in elderly patients undergoing colonoscopy and calculate incidence rate ratios for selected comparison groups.

Setting and Patients-Elderly patients undergoing colonoscopy.

Design-Systematic review and meta-analysis.

Main Outcome Measurements-Perforation, bleeding, cardiovascular (CV)/pulmonary complications, and mortality.

Results-Our literature search yielded 3328 articles, of which 20 studies met our inclusion criteria. Pooled incidence rates for adverse events (per 1000 colonoscopies) in patients 65 years of age and older were 26.0 (95\% CI, 25.0-27.0) for cumulative GI adverse events, 1.0 (95\% CI, 0.91.5) for perforation, 6.3 (95\% CI, 5.7-7.0) for GI bleeding, 19.1 (95\% CI, 18.0-20.3) for CV/ pulmonary complications, and 1.0 (95\% CI, 0.7-2.2) for mortality. Among octogenarians, adverse events (per 1000 colonoscopies) were as follows: cumulative GI adverse event rate of 34.9 (95\% CI, 31.9-38.0), perforation rate of 1.5 (95\% CI, 1.1-1.9), GI bleeding rate of 2.4 (95\% CI, 1.14.6), CV/pulmonary complication rate of 28.9 (95\% CI, 26.2-31.8), and mortality rate of 0.5 (95\% CI, 0.06-1.9). Patients 80 years of age and older experienced higher rates of cumulative GI adverse events (incidence rate ratio $1.7 ; 95 \% \mathrm{CI}, 1.5-1.9$ ) and had a greater risk of perforation (incidence rate ratio $1.6,95 \% \mathrm{CI}, 1.2-2.1$ ) compared with younger patients (younger than 80 years of age). There was an increased trend toward higher rates of GI bleeding and CV/pulmonary complications in octogenarians but neither was statistically significant.

Copyright @ 2011 by the American Society for Gastrointestinal Endoscopy

Reprint requests: Lukejohn W. Day, MD, San Francisco General Hospital, 1001 Potrero Avenue, 3D-5, San Francisco, CA 94110.

${ }_{1}^{1}$ Current affiliations: Division of Gastroenterology, San Francisco General Hospital, San Francisco, California.

${ }^{2}$ Current affiliations: GI Health Outcomes, Policy and Economics (HOPE) Research Program, Department of Medicine, University of California, San Francisco, California.

${ }^{3}$ Current affiliations: Department of Gastroenterology, California Pacific Medical Center, San Francisco, California.

${ }^{4}$ Current affiliations: Department of Medicine, Division of Gastroenterology and Hepatology, University of Washington, Seattle, Washington.

${ }^{5}$ Current affiliations: Division of Geriatrics, San Francisco VA Medical Center and University of California, San Francisco, California, USA.

DISCLOSURE: The authors disclosed no financial relationships relevant to this publication. This work was funded in part by grants from the Mount Zion Health Fund and American Society for Gastrointestinal Endoscopy Cook Career Development Award (M.S.) and from the National Institute of Diabetes and Digestive and Kidney Diseases (K24 DK080941) (J.M.I.). Dr. Walter is supported by a VA Health Services Research and Development grant IIR-04-427 and by grant 1R01CA134425 from the National Cancer Institute. 
Limitations-Heterogeneity of studies included and not all complications related to colonoscopy were captured.

Conclusions-Elderly patients, especially octogenarians, appear to have a higher risk of complications during and after colonoscopy. These data should inform clinical decision making, the consent process, public health policy, and comparative effectiveness analyses.

Colorectal cancer (CRC) remains the third leading cause of cancer-related deaths in the United States, ${ }^{1}$ with the incidence dramatically increasing with age. ${ }^{2}$ Optical colonoscopy has been endorsed by several societies as the preferred CRC screening strategy beginning at age 50 for its additional benefit to CRC prevention. ${ }^{3,4}$ Although there is consensus by most of when to initiate CRC screening, controversy exists regarding when to discontinue it, especially in our aging patient population. Some societies provide no upper age cutoff, ${ }^{4}$ whereas others recommend against screening in people older than 75 years of age and to factor an individual's health status into screening decisions. ${ }^{3}$

To justify the risks of colonoscopy, its effectiveness should be substantially higher than its alternatives. Recent data on colonoscopy suggest that both the limited effectiveness for detecting right-sided lesions 5,6 and inconsistent quality of colonoscopy may overestimate its protective effect. ${ }^{7}$ In the elderly, the net benefit of colonoscopy screening is reduced because of the competing risk of mortality from other diseases. ${ }^{8}$ Moreover, many elderly patients may no longer be receiving their initial colonoscopy, but rather are undergoing colonoscopy for surveillance purposes, in which the net benefit is further decreased. ${ }^{9}$ Two epidemiologic trends further highlight the impact that U.S. demographics have had on colonoscopy demand: Americans are living longer and the largest age cohort is now older than age 65 years. Although use of colonoscopy has increased substantially over the past decade, it will be in even greater demand among our aging population. ${ }^{10}$

Because the benefits of colonoscopy may be reduced in older adults, it is important to understand the balance of risks and benefits and make more informed decisions about undergoing colonoscopy at older ages. Few studies directly focus on age-specific complications related to colonoscopy, but some suggest that increasing age may play a role in adverse events. ${ }^{11-16}$ To date, no systematic review or meta-analysis comparing elderly and nonelderly patients with respect to adverse events and colonoscopy has been performed. A better understanding of the interaction between age and adverse events related to colonoscopy will allow physicians to conduct a more comprehensive and balanced informed consent process with elderly patients considering colonoscopy.

\section{METHODS}

\section{Study population}

We performed a systematic review of computerized bibliography databases for elderly patients who underwent colonoscopy. We defined elderly using the World Health Organization's definition of a patient 65 years of age and older. Studies were included if data pertaining to patients 65 years of age and older and documented adverse events related to colonoscopy were reported and could be abstracted. Colonoscopies may have been performed in either the outpatient or inpatient setting and could have been for screening, diagnostic, or therapeutic purposes. Two age strata were present in the literature: the elderly (those 65 years of age and older) and octogenarians (those 80 years of age and older).

We searched computerized bibliography databases including MEDLINE (1950 to March 1, 2010), EMBASE (1980 to March 1, 2010), and Cochrane Review Library (1992 to March 1, 2010). Search terms included "colonoscopy" combined with any of the following key words/ MeSH headings: "elderly," "complication," "adverse events," or specific complications 
relating to colonoscopy including "perforation," "mortality," "bleeding complications," "post-polypectomy bleeding," "cardiovascular complications," "respiratory complications," or "conscious sedation complications." Articles were limited to randomized, controlled trials and cohort studies with no restriction based on language. The reference lists of all retrieved articles were reviewed to identify additional studies. Last, a manual search of abstracts submitted to Digestive Disease Week and the American College of Gastroenterology Annual Conference (2001-2010) was performed.

\section{Data abstraction}

The following 4 categories of adverse events associated with a colonoscopy were abstracted from the full articles: (1) perforation, (2) GI bleeding (including postpolypectomy bleeding), (3) cardiovascular (CV)/pulmonary complications, and (4) mortality. Perforation was defined by a radiographic study obtained after a colonoscopy that demonstrated a perforation/free air requiring either surgical intervention or hospitalization. GI bleeding complications were defined as requiring at least a transfusion of 1 unit of packed red blood cells, admission to the hospital, postpolypectomy bleeding, or the need for a repeat endoscopic examination in the setting of rectal bleeding or anemia after a colonoscopy. CV/ pulmonary complications were defined by myocardial infarction, cerebrovascular accident, congestive heart failure, cardiac/respiratory arrest, arrhythmia, hypoxemia (oxygen saturation $<90 \%$ ), hypotension (systolic blood pressure $<90 \mathrm{~mm} \mathrm{Hg}$ ), bradycardia (heart rate $<60$ beats/min), tachycardia (heart rate $>110$ beats $/ \mathrm{min}$ ), or vasovagal response. Secondary data abstracted included colonoscopy completion rate, indication for colonoscopy, number of poor bowel preparations, mean insertion time to cecum, type of center where the study was performed, trainee involvement, follow-up time of patients for adverse events, mean amount of sedation used during colonoscopy, and proportion of patients who received sedation during their colonoscopy. Two authors (L.W.D., A.K.) independently screened and reviewed all titles, abstracts, and full articles for eligibility. If there was a discrepancy between the 2 reviewers, then a third author (M.S.) reviewed the article and a consensus was then reached among all 3 authors.

\section{Statistical analysis}

Adverse event primary outcomes were selected a priori based on their clinical importance and included perforation, GI bleeding, postpolypectomy bleeding, CV/pulmonary complications, and mortality. We used the investigators' assessment as to whether each of these adverse events was directly related to the performing of a colonoscopy.

The incidence rate of each primary outcome (using pooled data for each specific adverse event) was then calculated (adverse event per 1000 colonoscopies). Incidence rate calculations were based on 2 age strata: (1) patients 65 years of age and older and (2) patients 80 years of age and older. These 2 age strata were selected because studies involving adverse events and colonoscopy were overwhelmingly categorized according to these 2 age strata. We also calculated the incidence rate for cumulative GI adverse events, which included pooled adverse events for perforation, GI bleeding, and CV/pulmonary complications. Incidence rates for 2 subgroups of $\mathrm{CV} /$ pulmonary complications were also calculated and were stratified by severity: (1) severe (myocardial infarction, cerebrovascular accident, congestive heart failure, and cardiac/respiratory arrest) and (2) nonsevere (arrhythmia, hypoxemia, hypotension, bradycardia, tachycardia, and vasovagal response). Finally, we calculated incidence rates for primary outcomes based on follow-up time of reported adverse events after a colonoscopy according to the following classification: (1) at the time of the colonoscopy, (2) 7 days or less, or (3) 30 days or less. The calculated incidence rates and the $95 \%$ confidence intervals were calculated using the binomial distribution. 
A meta-analysis was then performed to examine the association between older and younger patients and the rates of adverse events. First, for patients 65 years of age and older versus younger than 65 years of age, an analysis could only be performed for perforation and mortality. An additional analysis was conducted for patients 65 years of age and older who did and did not undergo colonoscopy with respect to perforation. Second, for patients 80 years of age and older versus patients younger than 80 years of age, we analyzed cumulative GI adverse events, perforation, GI bleeding, CV/pulmonary complications, and mortality rate. Studies were assigned weights based on their sample size (number of included colonoscopies) as a function of the statistical test. The primary analysis was performed using the random-effects model, although a secondary analysis was performed using the fixedeffects model. Incidence rate ratios (IRRs) with 95\% confidence intervals were calculated for each analysis. Any differences observed between the results from the random-effects and fixed-effects analyses are stated in the Results section; otherwise, we only report the results using the random-effects model. A statistically significant result was observed with a $95 \%$ confidence interval and a $P$ value $<.05$. Not all studies ${ }^{15,17-25}$ used for the incidence rate calculations were included in the meta-analysis given that some studies did not have a younger age group with which to make a comparison. Sensitivity analyses were attempted to assess the effect of an indication for a colonoscopy (diagnostic vs nondiagnostic), therapeutic intervention (polypectomy vs no polypectomy), setting where colonoscopies were performed (academic center vs nonacademic center), trainee involvement, amount of sedation used, insertion time, and completion rates on specific adverse events in older and younger patients. However, insufficient data were available to stratify the data to this detail. As a result, sensitivity analyses could not be performed.

Heterogeneity was calculated using a $\chi^{2}$ test with n-1 degrees of freedom, where $\mathrm{n}$ represented the number of studies included with $P<.10$ representing significant heterogeneity. Kendall's tau was determined, and a funnel plot constructed to test for publication bias. All statistical analyses were calculated using Stata software version 11.0 (StataCorp, College Station, Texas).

\section{RESULTS}

Our initial search strategy yielded 3328 articles. After initial title and abstract review, 88 articles remained for full manuscript review. Sixty-eight articles were excluded with the most frequent reason being that both the number of colonoscopies and specific number of adverse events could not be abstracted from the articles and stratified into either 65 years of age and older or 80 years of age and older age groups (Fig. 1). Twenty articles remained for inclusion in the study with 3 studies having sufficiently detailed data for both patients 65 years of age and older and 80 years of age and older (Table 1).

Summary data pertaining to the performance of colonoscopies in the included studies are reported in Table 2. Among included studies with patients 65 years of age and older, the mean colonoscopic completion rate was $84.0 \pm 2.0 \%^{23,26,27}$ with poor bowel preparation documented in $18.8 \pm 6.4 \%$ of procedures. ${ }^{23,26}$ Similar observations were reported in studies examining patients 80 years of age and older with a mean colonoscopic completion rate of $84.7 \pm 11.7 \% 11,13-15,17-19,21,22,24,25,28$ and poor bowel preparation reported in $12.1 \pm$ $7.6 \% 14,17,19,21,22,24,25$ of colonoscopies. Included studies were overwhelmingly performed for a diagnostic indication in each age stratum with polyp surveillance constituting nearly one fifth of all indications for colonoscopy in octogenarians. More than half of the included studies were conducted at academic centers, but trainee participation was more frequent in studies with patients 65 years of age and older. 


\section{Incidence rates of adverse events related to colonoscopy}

Table 3 represents a summary of the incidence rates for specific adverse events related to colonoscopy stratified by patients 65 years of age and older and 80 years of age and older. Among patients 65 years of age and older, the cumulative GI adverse event rate was 26.0/1000 colonoscopies (95\% CI, 25.0-27.0). ${ }^{16,20,23,26}$ With respect to individual adverse events, the perforation rate was 1.0 perforation/1000 colonoscopies (95\% CI, 0.9$1.5),{ }^{12,16,20,23,26,27,29}$ whereas for GI bleeding (including polypectomy- and nonpolypectomy-related bleeding), the incidence rate was 6.3/1000 colonoscopies (95\% CI, 5.7-7.0). ${ }^{16,20,23,26}$ The greatest number of reported adverse events for patients 65 years of age and older pertained to CV/pulmonary adverse events (19.1/1000; 95\% CI, 18.020.3). ${ }^{16,20,23,26}$ Further stratification of CV/pulmonary adverse events revealed a nearly equal distribution among severe and nonsevere complications in this age group. There were 53 deaths documented in individuals 65 years of age and older among 4 studies, yielding a mortality incidence of 1.0 death/1000 (95\% CI, 0.7-2.2) colonoscopies. ${ }^{16,20,23,26}$ With respect to patient follow-up, the majority of studies that included patients 65 years of age and older followed their patients for up to 30 days after colonoscopy; specific adverse event rates by follow-up time are shown in Table 4 .

On the other hand, in patients 80 years of age and older, the incidence rate for cumulative GI adverse events was higher at 34.9/1000 colonoscopies (95\% CI, 31.938.0,). ${ }^{11,15-19,21,22,24,25,28}$ The calculated incidence rate for perforation was 1.5/1000 colonoscopies (95\% CI, 1.1-1.9), ${ }^{11,12,15,17-19,21,22,24,25,28-30}$ GI bleeding was 2.4/1000 colonoscopies (95\% CI, 1.1-4.6), ${ }^{11,15,17-19,21,22,24,25,28}$ and CV/pulmonary adverse events was $28.9 / 1000$ colonoscopies (95\% CI, 26.2-31.8). ${ }^{11,13-19,21,22,24,25,28}$ The majority of CV/ pulmonary complications in octogenarians were nonsevere, and among the nonsevere group, there were no resulting deaths. In patients 80 years of age and older, the mortality rate associated with colonoscopy was 0.5 deaths $/ 1000$ colonoscopies $(95 \%$ CI, 0.061.9), $, 11,13,15,17-19,21,22,24,25,28,30$ with only 2 deaths recorded in the literature for this age group. In contrast to studies stratifying patients older than 65 years of age, the majority of studies on octogenarians followed their patients for adverse events only on the day of the procedure (Table 4).

\section{Meta-analysis for adverse events in patients 65 years of age and older}

Patients 65 years of age and older who underwent colonoscopy had a 14-fold higher risk of perforation compared with patients of the same age who did not have a colonoscopy performed (IRR 13.7; 95\% CI, 2.5-75.9; $P=.001$ for heterogeneity).${ }^{16,29}$ An analysis using the fixed-effects model resulted in a further increase in perforation risk (IRR 19.6; 95\% CI, $13.1-29.4 ; P=.001$ for heterogeneity), but in both analyses, heterogeneity was present. Three studies ${ }^{26,27,29}$ compared patients 65 years of age and older with those younger than 65 years of age with respect to colonic perforation; however, only 1 of these studies ${ }^{29}$ reported an adverse event, with the remaining studies having no events in both age strata. There were 2 studies $^{23,26}$ in which data could be abstracted for mortality in patients 65 of age and older and patients younger than 65 years of age; however, there were no events ( 0 deaths) in either group.

\section{Meta-analysis for adverse events in patients $\mathbf{8 0}$ years of age and older}

Octogenarians had a $70 \%$ greater risk of experiencing a cumulative GI adverse event compared with younger patients (IRR 1.7; 95\% CI, 1.5-1.9; $P=.9$ for heterogeneity) (Fig. 2). ${ }^{11,16,28}$ Patients 80 years of age and older had a higher risk of perforation (IRR 1.6; $95 \%$ CI, $1.2-2.1 ; P=.9$ for heterogeneity) compared with patients younger than 80 years of age $11,12,28-30$ (Fig. 3). There was a similar trend toward elevated rates of GI bleeding ${ }^{11,28}$ (IRR 2.6; 95\% CI, $0.5-14.2 ; P=.7$ for heterogeneity) and CV/pulmonary adverse 
events $^{11,13,14,16,28}$ (IRR 1.3; 95\% CI, 0.8-2.2; $P=.02$ for heterogeneity); however, both results were not statistically significant, and heterogeneity was present in the CV/pulmonary analysis. When using the fixed-effects model, there was a statistically significant association for increased $\mathrm{CV} /$ pulmonary adverse events among octogenarians compared with younger patients (IRR 1.6; 95\% CI, 1.4-1.8; $P=.02$ for heterogeneity), although heterogeneity was present. Twelve studies had mortality data that could be abstracted for individuals 80 years and older, but only 4 studies ${ }^{11,13,28,30}$ were available to make a comparison with a younger cohort. When a meta-analysis was performed, there was an insufficient number of events present to make comparisons between both age groups.

Although only a limited number of studies were available, graphical inspection of the funnel plots and statistical analysis showed no evidence of significant publication bias (Figs. 4 and $5)$.

\section{DISCUSSION}

As individuals live longer, information regarding the differences in the risk of colonoscopy by age becomes increasingly important for patients and providers. In the articles retrieved for our study, the elderly overwhelmingly underwent colonoscopy for diagnostic purposes. Among individuals 65 years of age and older, the cumulative GI adverse event rate (perforation, bleeding, and CV/pulmonary) was 26.0/1000 colonoscopies, whereas in octogenarian patients, the cumulative adverse event rate increased to 34.9/1000 colonoscopies. By far, the most common adverse event for both age strata pertained to CV/ pulmonary complications. Additionally, octogenarians had a $70 \%$ increased risk of experiencing an adverse event and in particular, perforation was more likely to develop in older patients during or after colonoscopy. Although colonoscopy is generally considered safe, our data can help to refine clinical decision making, assist in the informed consent process, and aid in population-based policies, especially in our octogenarian population.

Many of our calculated incidence rates for patients older than 65 years of age fell within reported rates for patients of all ages undergoing colonoscopy, whereas more elevated rates of adverse events were observed in octogenarians. Adverse event rates for colonoscopy documented in the literature vary extensively and span several decades, with more recent data indicating that these rates have actually decreased. Specifically, the incidence rates for cumulative GI adverse events related to colonoscopy are 3.2/1000, ${ }^{31} 0.05-6.3 / 1000$ for perforation, ${ }^{29,32-44} 0.7-11.3 / 1000$ for GI bleeding, ${ }^{16,45-52}$ and 3.4-20.0/1000 for CV/ pulmonary, ${ }^{16,53-55}$ with a mortality rate of $0.06 / 1000 .{ }^{56}$ Although it is difficult to directly compare our incidence rates for the elderly with overall incidence rates that include all ages, there are several interesting trends. In particular, octogenarian patients appear to have a higher cumulative adverse event rate that is largely driven by higher CV/pulmonary complications. Further supporting this observation was a trend, although not statistically significant, of increased CV/pulmonary complications in patients older than 80 years of age compared with those younger than 80 years of age. Increased CV/pulmonary complications in the elderly have been reported, but other factors such as the American Society of Anesthesiologists classification, inpatient procedures, and trainee involvement are reportedly more predictive of cardiopulmonary events than age. ${ }^{53}$ Greater severity and number of comorbid medical conditions, older patients taking multiple medications, and altered physiology in response to sedation may all play a role in our observed trend of higher $\mathrm{CV} /$ pulmonary adverse event rates in octogenarians. Although there was a higher rate of $\mathrm{CV} /$ pulmonary adverse events in octogenarians, the vast majority of these were nonsevere, such as transient hypotension and hypoxia, which resulted in no major morbidity or mortality for patients. Our systematic review highlights that care should be taken in patients 
older than 80 years of age when discussing colonoscopy and such differences in risk, such as $\mathrm{CV} /$ pulmonary complications, need to be considered before performing colonoscopy.

Along the same lines, our incidence rate calculations showed a higher mortality rate in both patient groups compared with published data. Mortality is a rare, but dreaded complication of colonoscopy and in many circumstances is not an immediate event but can occur days to weeks after, making it difficult to track and report. The benefit of a systematic review and meta-analysis in pooling data can shed light on such limitations. Our pooled mortality incidence indicates that death appears to be higher in older patients than was previously reported. However, this result should be interpreted with some caution. Older patients in our study disproportionately underwent colonoscopy for diagnostic purposes rather than for screening, leading to confounding of risk by indication. We were unable to determine the cause-specific mortality or examine other contributing factors, such as comorbid medical conditions, which may play a role in mortality. Furthermore, we were unable to perform a meta-analysis with a younger cohort given that mortality was rare in both age strata. However, our data serve to further alert the clinician that elderly patients may be more susceptible to adverse outcomes during colonoscopy and that such risks need to be a factor in deciding whether colonoscopy is warranted.

A natural question that arises is how advanced age contributes to increased adverse events during colonoscopy. For example, in several of our analyses, we show that older patients have an increased risk of perforation compared with younger patients. In particular, octogenarians have a $60 \%$ greater risk of perforation compared with younger patients. A greater prevalence of diverticulosis, more tortuous colons, higher rates of CRC resulting in obstruction, and a greater probability of polyps requiring therapeutic intervention are all found more frequently in older patients, especially the very elderly, and are possible mechanisms for this increased risk. At the same time, a more challenging and longer colonoscopy may contribute to increased perforation rates in the elderly. Many endoscopists subjectively judge a colonoscopy in the elderly to be more difficult and require a longer time to intubate the cecum. ${ }^{57}$ Also, failure to successfully complete a colonoscopy is reported to be higher in older patients. ${ }^{14,58,59}$ However, among our included studies, there were scant adverse outcome data present to make meaningful comparisons between older and younger patients and these potential factors.

Our meta-analysis also raises the link between age and higher adverse events from GI bleeding (including post-polypectomy bleeding) and CV/pulmonary complications. Postpolypectomy bleeding rates are increased in patients with a greater burden of comorbid medical conditions, ${ }^{60}$ size/number of polyps removed, ${ }^{61-63}$ and therapeutic maneuvers such as a polypectomy ${ }^{62}$; all of these risk factors are likely greater in elderly patients who are known to have a higher incidence of adenomas ${ }^{64}$ and larger polyps. ${ }^{65,66}$ However, our metaanalysis was limited in that adverse events could not be stratified by age and polypectomy or by age and the size/number of polyps detected to determine whether an association existed. In addition, the increased CV/pulmonary adverse event rate observed in the elderly undergoing colonoscopy may be influenced by the greater number and severity of comorbid medical conditions commonly documented in older patients. ${ }^{53}$ Also, the amount of sedating medications given to patients during colonoscopy has been postulated to play a role in increased CV/pulmonary complications, with some arguing that elderly patients may receive more sedation than younger patients. Yet among the studies included in our systematic review, either no difference was noted between older and younger patients with regard to sedating medications, ${ }^{14,26}$ and in some cases, older patients received less medication. ${ }^{11,13,23}$

Several limitations exist with our study. First, other factors in addition to age may have contributed to our observation of an increased incidence of adverse events related to 
colonoscopy. Although age may serve as a surrogate for risk, the true mediator of risk could not be accounted for in this study, such as comorbid medical conditions ${ }^{16,29}$ and the type of procedure such as screening, diagnostic, or therapeutic colonoscopy. ${ }^{16}$ Second, we could not assess other adverse events such as hospitalizations, abdominal pain, and infections (diverticulitis, cholecystitis). In many cases, these were not reported, could not be extrapolated from the studies examined, or were documented only as case reports. Regardless, the outcomes of perforation, GI bleeding, CV/pulmonary complications, and mortality are consistently reported in studies addressing colonoscopy and are the most pertinent when discussing the risks of colonoscopy to patients. Third, information with respect to a patient's use of antiplatelet agents, nonsteroidal anti-inflammatory drugs, and Coumadin were not reported in our studies. Such information would have been useful for further analyses to identify if a difference existed in patients taking these agents and the risk of bleeding. Fourth, our study included mostly patients who underwent colonoscopy for diagnostic purposes and thus cannot be generalized to healthy patients undergoing screening colonoscopy. Additionally, discrepant patient follow-up times existed among studies for adverse event rates for patients 65 years of age and older and those 80 years of age and older (Table 4). Differences observed between these 2 age strata reflect the varying methodologies of the included studies rather than the timing of adverse events. For example, the majority of studies pertaining to patients older than 65 years of age were retrospective in nature, using claims data to capture adverse events. All of these studies included a much longer time interval ( $\unlhd-30$ days) to accommodate for adverse event reporting using International Classification of Diseases, 9th Revision codes. In contrast, studies examining octogenarians overwhelmingly relied on direct patient follow-up or endoscopy reports/medical records to document adverse events and thus used a shorter time interval (ie, day of the procedure) for patient follow-up. Also, we were unable to further investigate the association of age with other potential risk factors for adverse outcomes such as completion rates, insertion time, procedure indication, and therapeutic intervention, given the lack of such reported data in the literature. Last, a further limitation of this study is that few studies were available in which meta-analyses could be performed with respect to specific adverse events, thereby limiting the generalizability of our results.

In summary, we determined that differences in colonoscopic adverse events with respect to age exist, but mostly in octogenarians and in those undergoing diagnostic colonoscopy.

Octogenarians were more likely than younger patients to experience an adverse event and in particular had a greater chance of a perforation developing. Additionally, we identified that among octogenarians it appears that they have higher rates of CV/pulmonary adverse events, but in most cases, these were nonsevere with no associated mortality. Our data on the risk of performing colonoscopy in older patients, and specifically octogenarians who may be undergoing diagnostic or surveillance colonoscopy, should be integrated into the discussions that we have with our patients and their families when considering colonoscopy, including the informed consent process as well as decision algorithms in deciding the utility of performing a colonoscopy. Our age-specific incidence of adverse events provides additional point estimates for decision analytical modeling, which may critically examine the balance of cost, risk, and benefit of CRC surveillance strategies in the elderly.

\section{Abbreviations}

$\begin{array}{ll}\text { CRC } & \text { colorectal cancer } \\ \text { CV } & \text { cardiovascular } \\ \text { IRR } & \text { incidence rate ratio }\end{array}$




\section{References}

1. Jemal A, Siegel R, Ward E, et al. Cancer statistics, 2009. CA Cancer J Clin. 2009; 59:225-49. [PubMed: 19474385]

2. Rabeneck L, El-Serag HB, Davila JA, et al. Outcomes of colorectal cancer in the United States: no change in survival (1986-1997). Am J Gastroenterol. 2003; 98:471-7. [PubMed: 12591071]

3. Screening for colorectal cancer: U. S Preventive Services Task Force recommendation statement. Ann Intern Med. 2008; 149:627-37. [PubMed: 18838716]

4. McFarland EG, Levin B, Lieberman DA, et al. Revised colorectal screening guidelines: joint effort of the American Cancer Society, U.S. Multisociety Task Force on Colorectal Cancer, and American College of Radiology. Radiology. 2008; 248:717-20. [PubMed: 18710970]

5. Baxter NN, Goldwasser MA, Paszat LF, et al. Association of colonoscopy and death from colorectal cancer. Ann Intern Med. 2009; 150:1-8. [PubMed: 19075198]

6. Brenner H, Hoffmeister M, Arndt V, et al. Protection from right- and left-sided colorectal neoplasms after colonoscopy: population-based study. J Natl Cancer Inst. 2010; 102:89-95. [PubMed: 20042716]

7. Barclay RL, Vicari JJ, Doughty AS, et al. Colonoscopic withdrawal times and adenoma detection during screening colonoscopy. N Engl J Med. 2006; 355:2533-41. [PubMed: 17167136]

8. Kahi CJ, Azzouz F, Juliar BE, et al. Survival of elderly persons undergoing colonoscopy: implications for colorectal cancer screening and surveillance. Gastrointest Endosc. 2007; 66:54450. [PubMed: 17725944]

9. Saini SD, Schoenfeld P, Vijan S. Surveillance colonoscopy is cost-effective for patients with adenomas who are at high risk of colorectal cancer. Gastroenterology. 2010; 138:2292-9. 2299.e1. [PubMed: 20226186]

10. Singh H, Demers AA, Xue L, et al. Time trends in colon cancer incidence and distribution and lower gastrointestinal endoscopy utilization in Manitoba. Am J Gastroenterol. 2008; 103:1249-56. [PubMed: 18190650]

11. Arora A, Singh P. Colonoscopy in patients 80 years of age and older is safe, with high success rate and diagnostic yield. Gastrointest Endosc. 2004; 60:408-13. [PubMed: 15332032]

12. Gatto NM, Frucht H, Sundararajan V, et al. Risk of perforation after colonoscopy and sigmoidoscopy: a population-based study. J Natl Cancer Inst. 2003; 95:230-6. [PubMed: 12569145]

13. Lagares-Garcia JA, Kurek S, Collier B, et al. Colonoscopy in octogenarians and older patients. Surg Endosc. 2001; 15:262-5. [PubMed: 11344425]

14. Lukens FJ, Loeb DS, Machicao VI, et al. Colonoscopy in octogenarians: a prospective outpatient study. Am J Gastroenterol. 2002; 97:1722-5. [PubMed: 12135025]

15. Sardinha TC, Nogueras JJ, Ehrenpreis ED, et al. Colonoscopy in octogenarians: a review of 428 cases. Int J Colorectal Dis. 1999; 14:172-6. [PubMed: 10460909]

16. Warren JL, Klabunde CN, Mariotto AB, et al. Adverse events after outpatient colonoscopy in the Medicare population. Ann Intern Med. 2009; 150:849-57. W152. [PubMed: 19528563]

17. Perry WB, Opelka FG, Terrell HC, et al. Geriatric colonoscopy. Perspect Colon Rectal Surg. 2000; 13:93-100.

18. Bat L, Pines A, Shemesh E, et al. Colonoscopy in patients aged 80 years or older and its contribution to the evaluation of rectal bleeding. Postgrad Med J. 1992; 68:355-8. [PubMed: 1630980]

19. Chatrenet P, Friocourt P, Ramain JP, et al. Colonoscopy in the elderly: a study of 200 cases. Eur J Med. 1993; 2:411-3. [PubMed: 8258030]

20. DiPrima RE, Barkin JS, Blinder M, et al. Age as a risk factor in colonoscopy: fact versus fiction. Am J Gastroenterol. 1988; 83:123-5. [PubMed: 3341334]

21. Fontagnier EM, Manegold BC. Colonoscopy in patients over 80 years of age. Indications, methods and results [in German]. Dtsch Med Wochenschr. 2000; 125:1319-22. [PubMed: 11109413]

22. George ML, Tutton MG, Jadhav VV, et al. Colonoscopy in older patients: a safe and sound practice. Age Ageing. 2002; 31:80-1. [PubMed: 11850317] 
23. Ma WT, Mahadeva S, Kunanayagam S, et al. Colonoscopy in elderly Asians: a prospective evaluation in routine clinical practice. J Dig Dis. 2007; 8:77-81. [PubMed: 17532819]

24. Syn WK, Tandon U, Ahmed MM. Colonoscopy in the very elderly is safe and worthwhile. Age Ageing. 2005; 34:510-3. [PubMed: 16107458]

25. Duncan JE, Sweeney WB, Trudel JL, et al. Colonoscopy in the elderly: low risk, low yield in asymptomatic patients. Dis Colon Rectum. 2006; 49:646-51. [PubMed: 16482421]

26. Karajeh MA, Sanders DS, Hurlstone DP. Colonoscopy in elderly people is a safe procedure with a high diagnostic yield: a prospective comparative study of 2000 patients. Endoscopy. 2006; 38:226-30. [PubMed: 16528647]

27. Nelson DB, McQuaid KR, Bond JH, et al. Procedural success and complications of large-scale screening colonoscopy. Gastrointest Endosc. 2002; 55:307-14. [PubMed: 11868001]

28. Tsutsumi S, Fukushima H, Osaki K, et al. Feasibility of colonoscopy in patients 80 years of age and older. Hepatogastroenterology. 2007; 54:1959-61. [PubMed: 18251138]

29. Arora G, Mannalithara A, Singh G, et al. Risk of perforation from a colonoscopy in adults: a large population-based study. Gastrointest Endosc. 2009; 69:654-64. [PubMed: 19251006]

30. Ko CW, Riffle S, Shapiro JA, et al. Incidence of minor complications and time lost from normal activities after screening or surveillance colonoscopy. Gastrointest Endosc. 2007; 65:648-56. [PubMed: 17173914]

31. Ko CW, Riffle S, Michaels L, et al. Serious complications within 30 days of screening and surveillance colonoscopy are uncommon. Clin Gastroenterol Hepatol. 2010; 8:166-73. [PubMed: 19850154]

32. Sieg A, Hachmoeller-Eisenbach U, Eisenbach T. Prospective evaluation of complications in outpatient GI endoscopy: a survey among German gastroenterologists. Gastrointest Endosc. 2001; 53:620-7. [PubMed: 11323588]

33. Biandrate F, Piccolini M, Francia L, et al. Colonic perforation after colonoscopy: our experience. Chir Ital. 2003; 55:617-20. [PubMed: 12938614]

34. Christie JP, Marrazzo J 3rd. "Mini-perforation" of the colon-not all post-polypectomy perforations require laparotomy. Dis Colon Rectum. 1991; 34:132-5. [PubMed: 1993410]

35. Dafnis G, Ekbom A, Pahlman L, et al. Complications of diagnostic and therapeutic colonoscopy within a defined population in Sweden. Gastrointest Endosc. 2001; 54:302-9. [PubMed: 11522969]

36. Garcia Martinez MT, Ruano Poblador A, Galan Raposo L, et al. Perforation after colonoscopy: our 16-year experience [in Spanish]. Rev Esp Enferm Dig. 2007; 99:588-92. [PubMed: 18052662]

37. Iqbal CW, Chun YS, Farley DR. Colonoscopic perforations: a retrospective review. J Gastrointest Surg. 2005; 9:1229-35. discussion 36. [PubMed: 16332478]

38. Kang HY, Kang HW, Kim SG, et al. Incidence and management of colonoscopic perforations in Korea. Digestion. 2008; 78:218-23. [PubMed: 19142003]

39. Levin TR, Zhao W, Conell C, et al. Complications of colonoscopy in an integrated health care delivery system. Ann Intern Med. 2006; 145:880-6. [PubMed: 17179057]

40. Lohsiriwat V, Sujarittanakarn S, Akaraviputh T, et al. Colonoscopic perforation: a report from World Gastroenterology Organization endoscopy training center in Thailand. World J Gastroenterol. 2008; 14:6722-5. [PubMed: 19034978]

41. Misra T, Lalor E, Fedorak RN. Endoscopic perforation rates at a Canadian university teaching hospital. Can J Gastroenterol. 2004; 18:221-6. [PubMed: 15054498]

42. Nassiopoulos K, Chanson C, Petropoulos P. Perforation of the colon during colonoscopy [in French]. Swiss Surg. 1999; 5:2-5. [PubMed: 10073123]

43. Singh H, Penfold RB, DeCoster C, et al. Colonoscopy and its complications across a Canadian regional health authority. Gastrointest Endosc. 2009; 69:665-71. [PubMed: 19251007]

44. Brynitz S, Kjaergard H, Struckmann J. Perforations from colonoscopy during diagnosis and treatment of polyps. Ann Chir Gynaecol. 1986; 75:142-5. [PubMed: 3740781]

45. Jentschura D, Raute M, Winter J, et al. Complications in endoscopy of the lower gastrointestinal tract. Therapy and prognosis Surg Endosc. 1994; 8:672-6. 
46. Macrae FA, Tan KG, Williams CB. Towards safer colonoscopy: a report on the complications of 5000 diagnostic or therapeutic colonoscopies. Gut. 1983; 24:376-83. [PubMed: 6601604]

47. Mandel JS, Bond JH, Church TR, et al. Reducing mortality from colorectal cancer by screening for fecal occult blood. Minnesota Colon Cancer Control Study. N Engl J Med. 1993; 328:1365-71. [PubMed: 8474513]

48. Nivatvongs S. Complications in colonoscopic polypectomy: lessons to learn from an experience with 1576 polyps. Am Surg. 1988; 54:61-3. [PubMed: 3341645]

49. Smith LE. Fiberoptic colonoscopy: complications of colonoscopy and polypectomy. Dis Colon Rectum. 1976; 19:407-12. [PubMed: 1084827]

50. Waye JD, Lewis BS, Yessayan S. Colonoscopy: a prospective report of complications. J Clin Gastroenterol. 1992; 15:347-51. [PubMed: 1294644]

51. Wexner SD, Garbus JE, Singh JJ. A prospective analysis of 13,580 colonoscopies. Reevaluation of credentialing guidelines. Surg Endosc. 2001; 15:251-61. [PubMed: 11344424]

52. Zubarik R, Fleischer DE, Mastropietro C, et al. Prospective analysis of complications 30 days after outpatient colonoscopy. Gastrointest Endosc. 1999; 50:322-8. [PubMed: 10462650]

53. Sharma VK, Nguyen CC, Crowell MD, et al. A national study of cardiopulmonary unplanned events after GI endoscopy. Gastrointest Endosc. 2007; 66:27-34. [PubMed: 17591470]

54. Silvis SE, Nebel O, Rogers G, et al. Endoscopic complications. Results of the 1974 American Society for Gastrointestinal Endoscopy Survey. JAMA. 1976; 235:928-30. [PubMed: 128642]

55. Benjamin SB. Complications of conscious sedation. Gastrointest Endosc Clin N Am. 1996; 6:27786. [PubMed: 8673328]

56. Waye JD, Kahn O, Auerbach ME. Complications of colonoscopy and flexible sigmoidoscopy. Gastrointest Endosc Clin N Am. 1996; 6:343-77. [PubMed: 8673332]

57. Ristikankare M, Hartikainen J, Heikkinen M, et al. The effects of gender and age on the colonoscopic examination. J Clin Gastroenterol. 2001; 32:69-75. [PubMed: 11154176]

58. Schmilovitz-Weiss H, Weiss A, Boaz M, et al. Predictors of failed colonoscopy in nonagenarians: a single-center experience. J Clin Gastroenterol. 2007; 41:388-93. [PubMed: 17413608]

59. Ure T, Dehghan K, Vernava AM 3rd, et al. Colonoscopy in the elderly. Low risk, high yield. Surg Endosc. 1995; 9:505-8. [PubMed: 7676371]

60. Rabeneck L, Paszat LF, Hilsden RJ, et al. Bleeding and perforation after outpatient colonoscopy and their risk factors in usual clinical practice. Gastroenterology. 2008; 135:1899-906. 1906.e1. [PubMed: 18938166]

61. Heldwein W, Dollhopf M, Rosch T, et al. The Munich Polypectomy Study (MUPS): prospective analysis of complications and risk factors in 4000 colonic snare polypectomies. Endoscopy. 2005; 37:1116-22. [PubMed: 16281142]

62. Paspatis GA, Vardas E, Theodoropoulou A, et al. Complications of colonoscopy in a large public county hospital in Greece. A 10-year study. Dig Liver Dis. 2008; 40:951-7. [PubMed: 18417433]

63. Watabe H, Yamaji Y, Okamoto M, et al. Risk assessment for delayed hemorrhagic complication of colonic polypectomy: polyp-related factors and patient-related factors. Gastrointest Endosc. 2006; 64:73-8. [PubMed: 16813806]

64. Lieberman DA, Weiss DG, Bond JH, et al. Use of colonoscopy to screen asymptomatic adults for colorectal cancer. Veterans Affairs Cooperative Study Group 380. N Engl J Med. 2000; 343:1628. [PubMed: 10900274]

65. Correa P, Strong JP, Reif A, et al. The epidemiology of colorectal polyps: prevalence in New Orleans and international comparisons. Cancer. 1977; 39:2258-64. [PubMed: 870171]

66. Eide TJ, Stalsberg H. Polyps of the large intestine in Northern Norway. Cancer. 1978; 42:2839-48. [PubMed: 728878] 


\section{Take-home Message}

- The cumulative GI adverse event rate for individuals 65 years of age and older and 80 years of age and older is higher than previously reported. Octogenarians have higher rates of developing a perforation when undergoing colonoscopy compared with younger patients.

- These data will help to inform clinical decision making, the informed consent process, and population-based policies. 


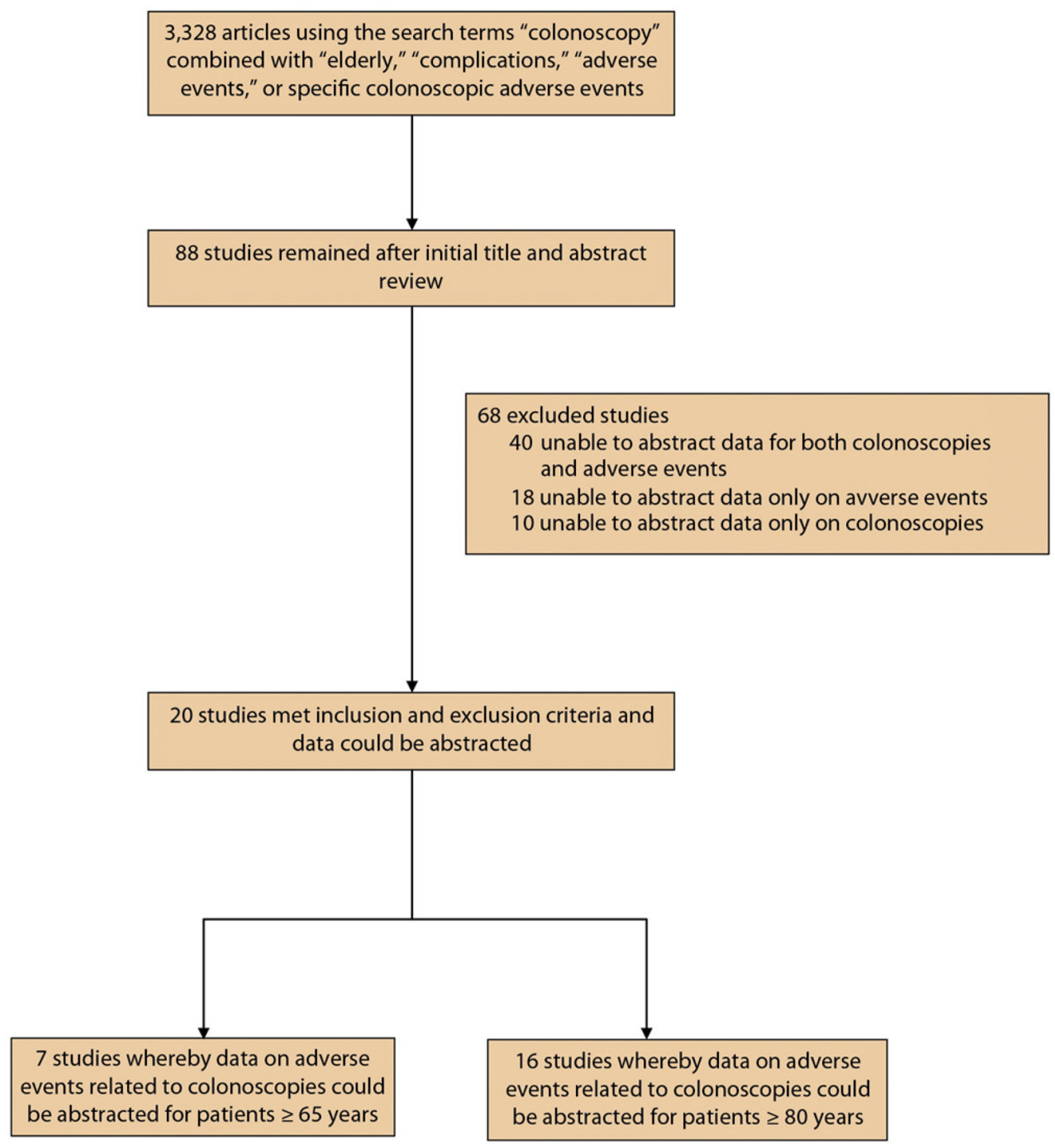

Figure 1.

Study flow diagram of the inclusion and exclusion of studies for the systematic review and meta-analysis for adverse events in older patients undergoing colonoscopy. Data from 3 of the included studies could be abstracted for both age stratifications. 


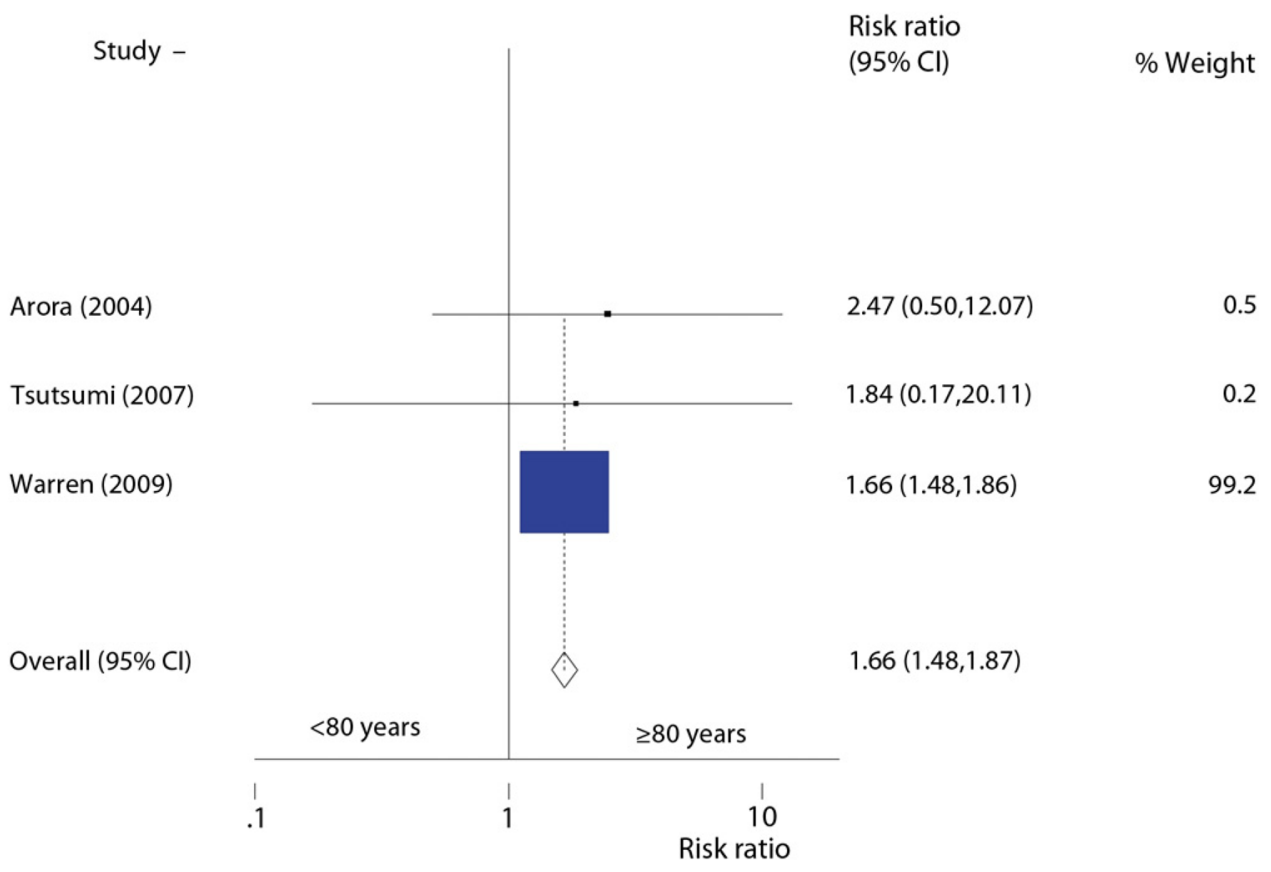

Figure 2.

Incidence rate ratio for patients 80 years of age and older versus those younger than 80 years of age with respect to a cumulative GI adverse event developing (perforation, GI bleeding, or cardiovascular/pulmonary) during or after colonoscopy. 


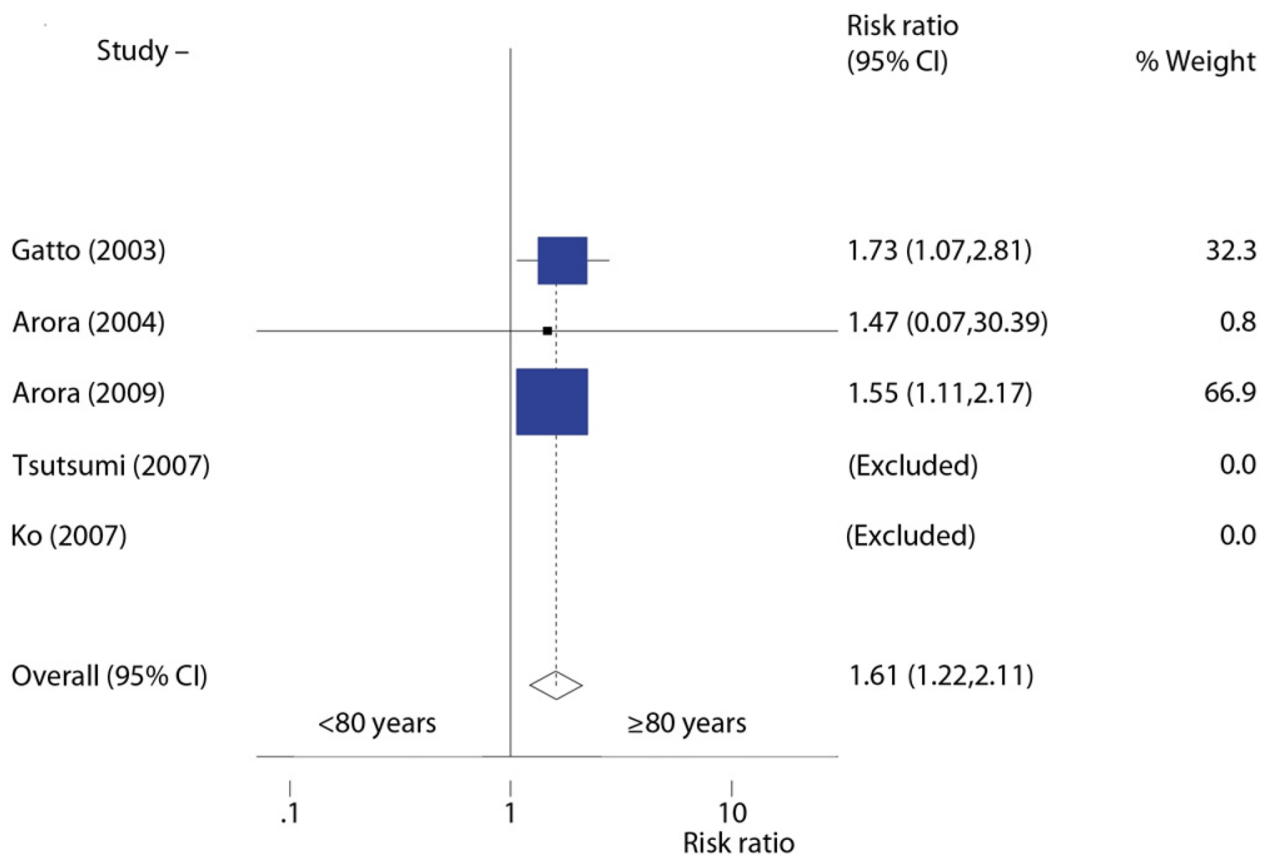

Figure 3.

Incidence rate ratio for patients 80 years of age and older versus those younger than 80 years of age with respect to a developing perforation during or after colonoscopy developing. 


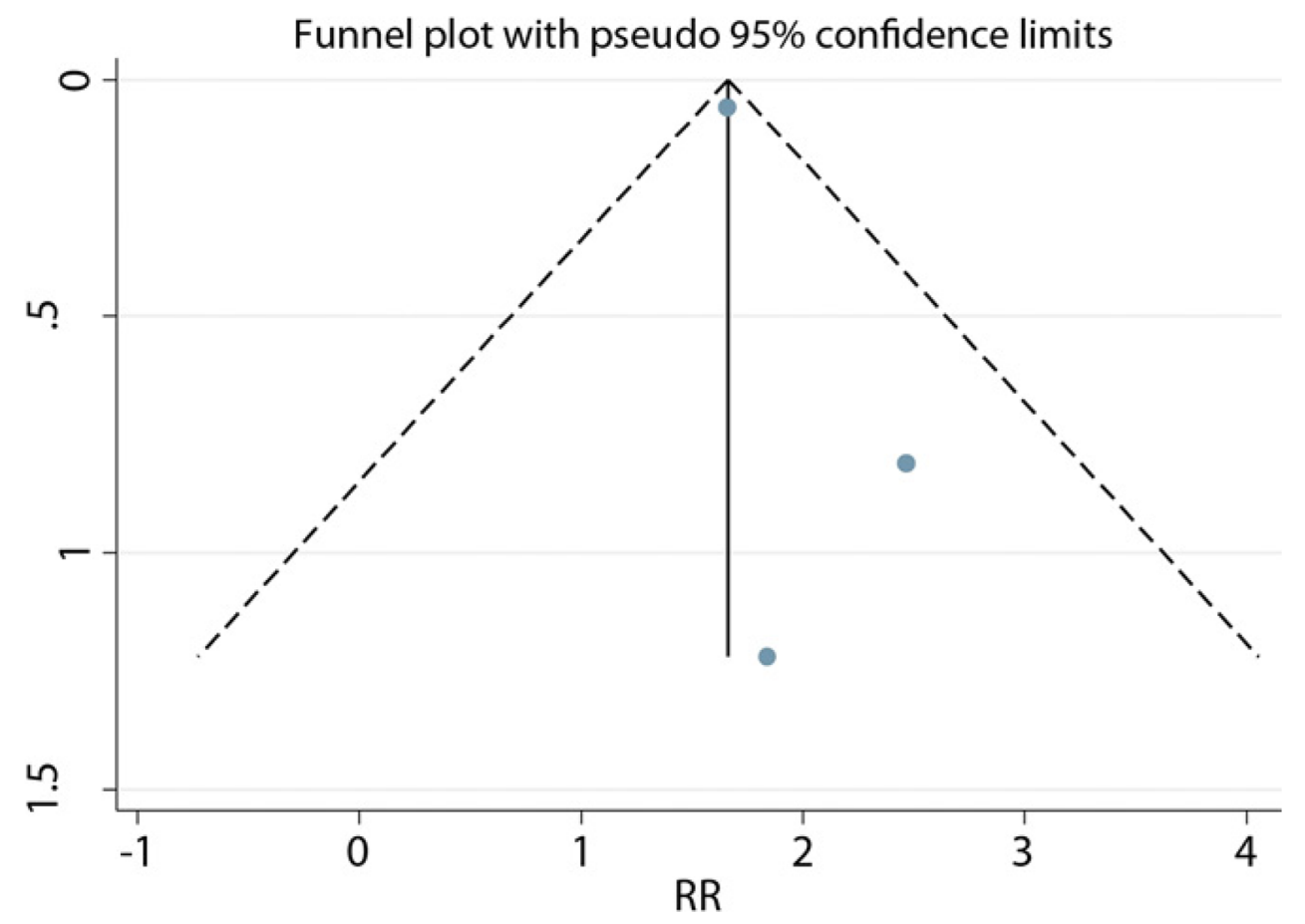

Figure 4.

Funnel plot for meta-analysis involving patients 80 years of age and older versus those younger than 80 years of age for cumulative GI adverse events. 


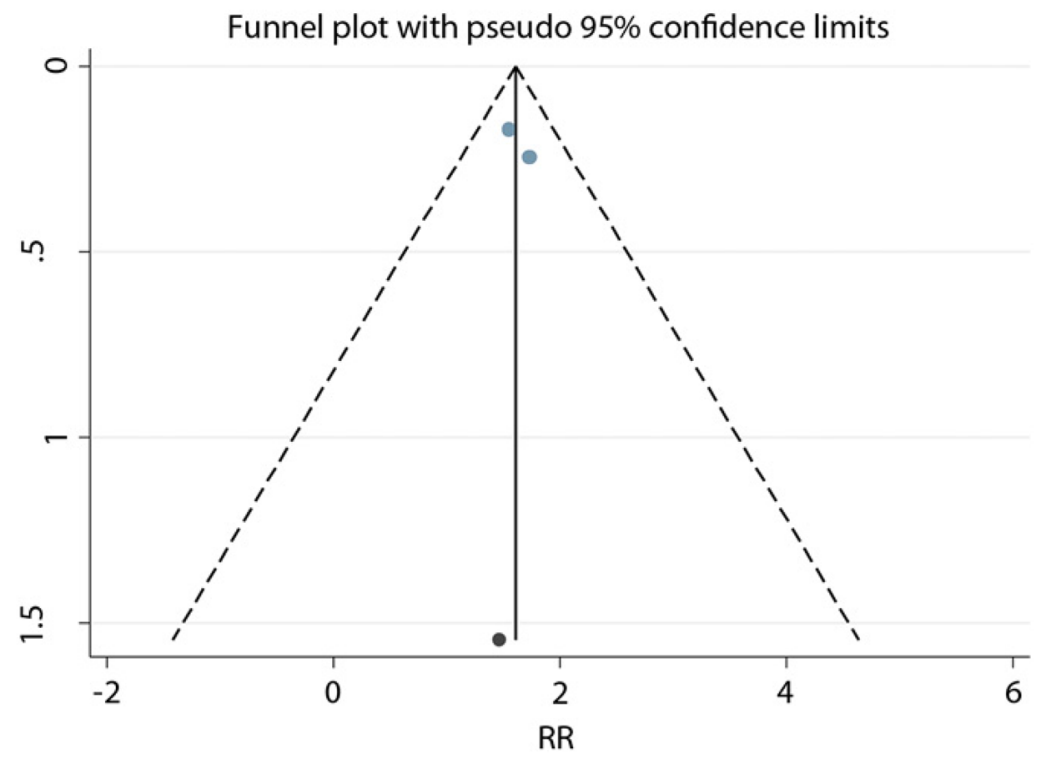

Figure 5.

Funnel plot for meta-analysis involving patients 80 years of age and older versus those younger than 80 years of age for perforations. 


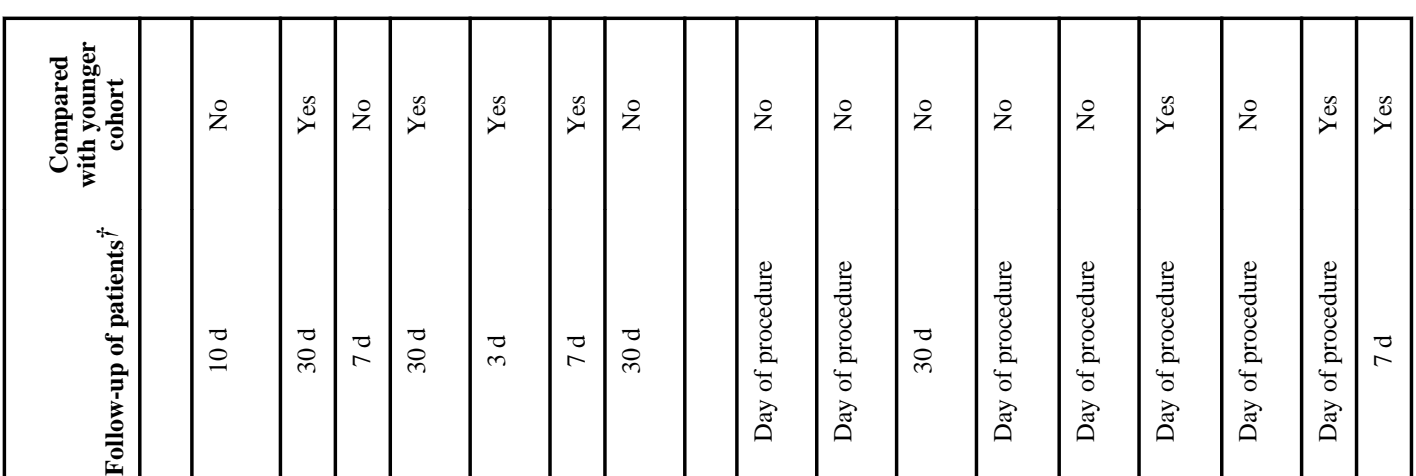

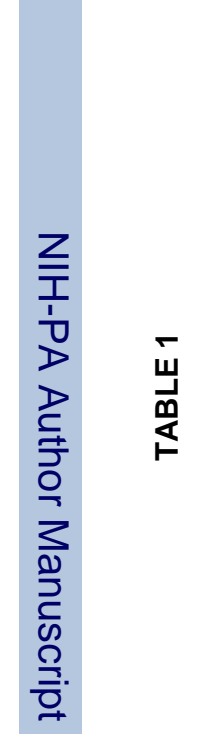

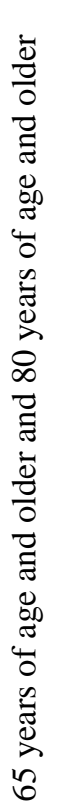

竧

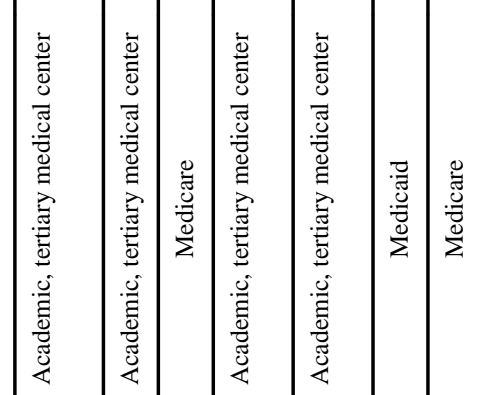

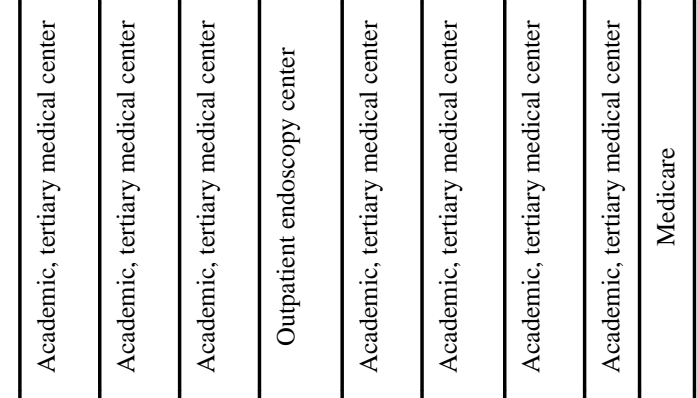

(n)

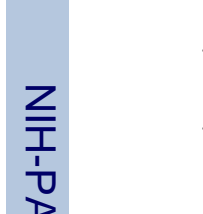

焉

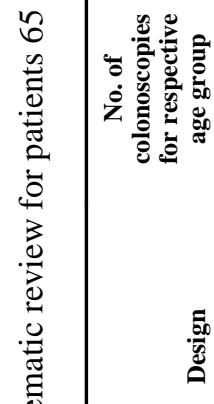

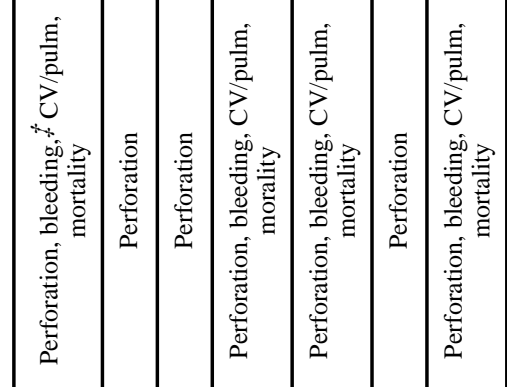

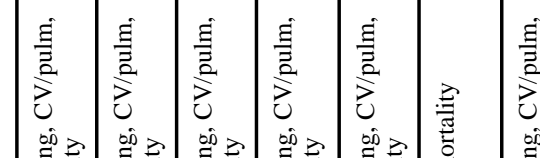

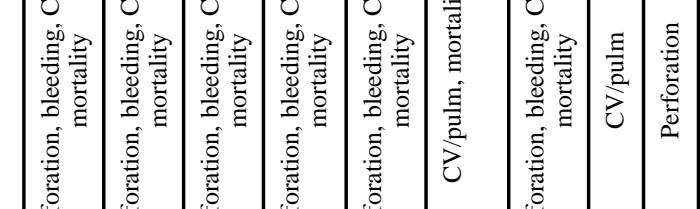

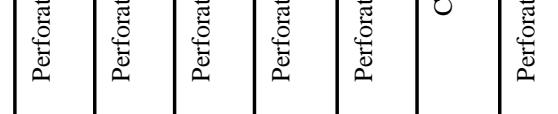

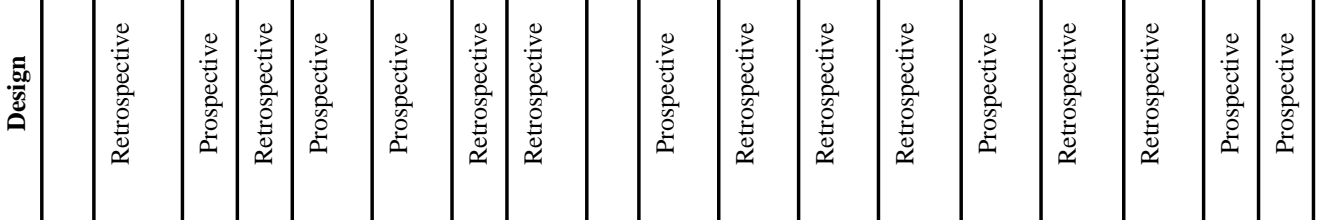

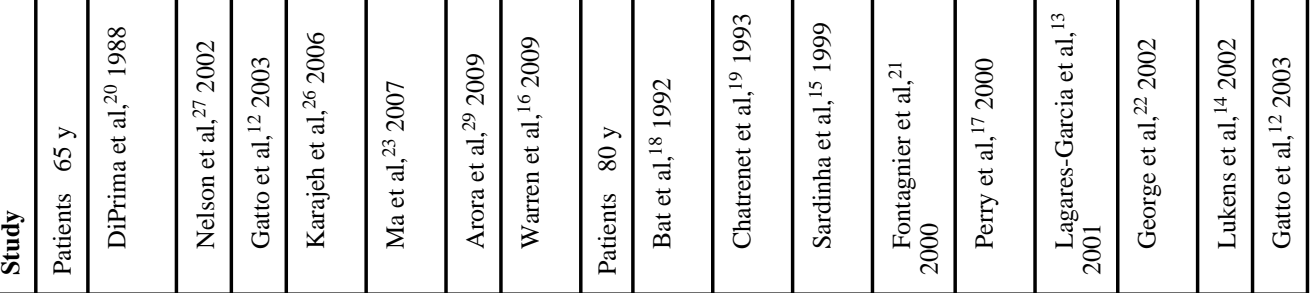




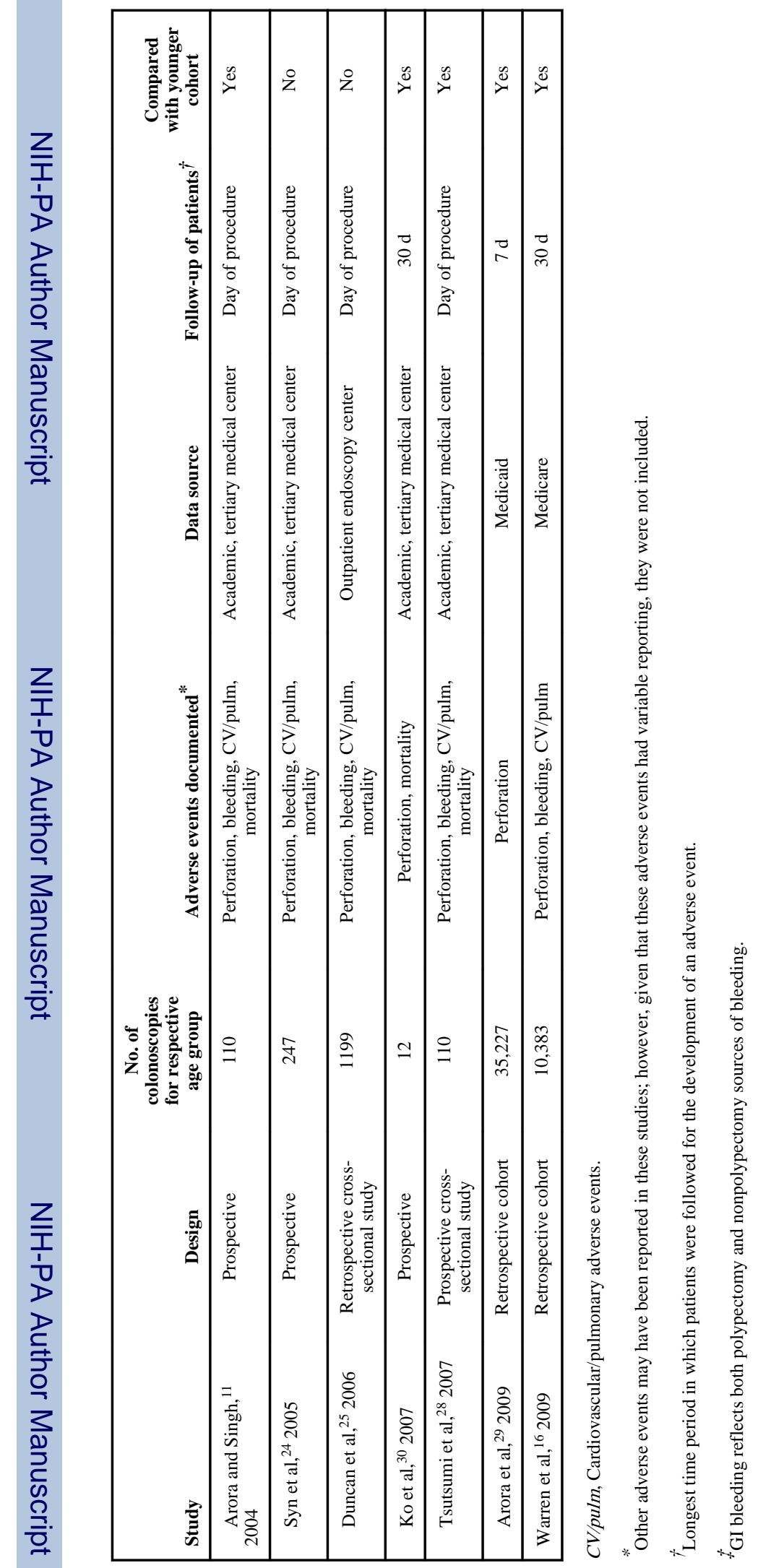

Gastrointest Endosc. Author manuscript; available in PMC 2012 October 01. 
TABLE 2

Data pertaining to the performance characteristics of colonoscopy for studies included in the systematic review

\begin{tabular}{|lcc|}
\hline & Studies with patients $\mathbf{x 5} \mathbf{y}$ & Studies with patients $\mathbf{8 0} \mathbf{y}$ \\
\hline Colonoscopy completion rate, $\%$ & $84.0 \pm 2.0^{23,26,27}$ & $84.7 \pm 11.7^{11,13-15,17-19,21,22,24,25,28}$ \\
\hline Poor bowel preparation, $\%$ & $18.8 \pm 6.4^{23,26}$ & $12.1 \pm 7.6^{14,17,19,21,22,24,25}$ \\
\hline Indication for colonoscopy, $\%$ & & \\
\hline Diagnostic & $58.1 \pm 33.5^{12,16,20,23,26,27}$ & $80.0 \pm 17.4^{11,13-15,17,19,21,22,24,25,28}$ \\
\hline Polyp surveillance & $13.7 \pm 16.3$ & $18.8 \pm 16.3$ \\
\hline Screening & $28.2 \pm 40.0$ & $1.2 \pm 2.4$ \\
\hline Colonoscopy performed at academic center, $\%$ & $57.1 \pm 53.5^{12,16,20,23,26,27,29}$ & $68.8 \pm 47.9^{11-19,21,22,24,25,28-30}$ \\
\hline Trainee participation in colonoscopy, $\%$ & $60.0 \pm 54.8^{12,20,23,26,27}$ & $28.6 \pm 46.9^{11-15,17-19,21,22,24,25,28,30}$ \\
\hline Sedation received during colonoscopy, $\%$ & $89.4 \pm 20.3^{20,23,26,27}$ & $96.8 \pm 9.3^{11,13-15,17-19,21,22,24,25,28,30}$ \\
\hline Total sedation received, mg & $4.3 \pm 0.6^{23,26}$ & $2.4 \pm 1.3^{11,13,14,24}$ \\
\hline Midazolam & N/A & $33.4 \pm 22.6^{11,13,14}$ \\
\hline Demerol & N/A * & $13.4 \pm 5.1^{11,13}$ \\
\hline Insertion time, min & & \\
\hline
\end{tabular}

Values shown are \pm standard deviation.

$N / A$, Not available.

Data only available from 1 study. 


\section{TABLE 3}

Summary of calculated incidence rates for specific adverse events related to colonoscopy stratified by patients 65 years of age and older and 80 years of age and older

\begin{tabular}{|c|c|c|}
\hline & No. of adverse events/no. of colonoscopies & Incidence per 1000 colonoscopies $(95 \% \mathrm{CI})$ \\
\hline \multicolumn{3}{|l|}{ Patients $\geq 65 \mathrm{y}$} \\
\hline Cumulative GI adverse events & $1419 / 54,592$ & $26.0(25.0-27.0)$ \\
\hline Perforation & $254 / 248,732$ & $1.0(0.9-1.5)$ \\
\hline GI bleeding & $345 / 54,592$ & $6.3(5.7-7.0)$ \\
\hline Postpolypectomy bleeding ${ }^{*}$ & $5 / 1372$ & $3.6(1.2-8.5)$ \\
\hline $\mathrm{CV} / \mathrm{pulm}$ & $1044 / 54,592$ & $19.1(18.0-20.3)$ \\
\hline Severe $^{t}$ & $661 / 54,592$ & $12.1(11.2-13.1)$ \\
\hline Nonsevere ${ }^{\dagger}$ & $753 / 54,592$ & $13.8(12.8-14.8)$ \\
\hline Mortality & $53 / 54,592$ & $1.0(0.7-2.2)$ \\
\hline \multicolumn{3}{|l|}{ Patients $280 \mathrm{y}$} \\
\hline Cumulative GI adverse events & $491 / 14,082$ & $34.9(31.9-38.0)$ \\
\hline Perforation & $71 / 47,076$ & $1.5(1.1-1.9)$ \\
\hline GI bleeding & $9 / 3699$ & $2.4(1.1-4.6)$ \\
\hline Postpolypectomy bleeding & $9 / 3699$ & $2.4(1.1-4.6)$ \\
\hline $\mathrm{CV} /$ pulm & $413 / 14,285$ & $28.9(26.2-31.8)$ \\
\hline Severe ${ }^{t}$ & $2 / 3902$ & $0.5(0.06-1.9)$ \\
\hline Nonsevere $f$ & $126 / 3902$ & $32.3(27.0-38.3)$ \\
\hline Mortality & $2 / 3814$ & $0.5(0.06-1.9)$ \\
\hline
\end{tabular}

CI, Confidence interval; CV/pulm, cardiovascular/pulmonary.

Data only available from 3 studies. ${ }^{20,23,26}$

${ }^{\dagger}$ Severe and nonsevere CV/pulmonary adverse events do not add up to the total CV/pulmonary adverse events because patients may have had more than 1 adverse event in each subgroup.

Severe and nonsevere CV/pulmonary adverse events do not add up to the total CV/pulmonary adverse events because data from the Warren et $\mathrm{al}^{16}$ study could not be abstracted into severe and nonsevere for patients 80 years of age and older. 
TABLE 4

Incidence rates for specific adverse events related to colonoscopy stratified by longest patient follow-up time

\begin{tabular}{|c|c|c|c|}
\hline & $\begin{array}{c}\text { Day of procedure (incidence per } 1000 \\
\text { colonoscopies) }\end{array}$ & $\begin{array}{l}\leq 7 \mathrm{~d} \text { (incidence per } 1000 \\
\text { colonoscopies) }\end{array}$ & $\begin{array}{l}30 \mathrm{~d} \text { (incidence per } 1000 \\
\text { colonoscopies) }\end{array}$ \\
\hline \multicolumn{4}{|l|}{ Patients $265 \mathrm{y}^{*}$} \\
\hline Perforation ${ }^{\dagger}$ & $\not$ & $1.1(1.0-1.3)^{12,20,23,29}$ & $0.6(0.4-0.9)^{16,20,26,27}$ \\
\hline GI bleeding & $\xi$ & $0(0.1-23.6)^{20,23}$ & $6.3(5.7-7.1)^{16,20,26}$ \\
\hline $\mathrm{CV} /$ pulm & // & $51.3(26.8-87.9)^{20,23}$ & $19.0(17.9-20.2)^{16,20,26}$ \\
\hline Mortality & II & $0(0.1-23.6)^{20,23}$ & $1.0(0.7-1.3)^{16,20,26}$ \\
\hline \multicolumn{4}{|l|}{ Patients $\geq 80 \mathrm{y}$} \\
\hline Perforation $^{\# * *}$ & $1.5(0.5-3.6)^{11,17-19,21,22,24,25,28}$ & $1.5(1.2-1.9)^{12,29}$ & $0(0.06-12.6)^{15,30}$ \\
\hline GI bleeding ${ }^{\#}$ & $2.5(1.1-4.8)^{11,17-19,21,22,24,25,28}$ & $\dagger t$ & $\xi \xi$ \\
\hline $\mathrm{CV} /$ pulm ${ }^{\#}$ & $12.4(9.0-16.6)^{11,13,14,17-19,21,22,24,25,28}$ & $\phi t$ & $34.2(30.9-37.8)^{15,16}$ \\
\hline Mortality ${ }^{* * *}$ & $0.6(0.07-2.1)^{11,13,17-19,21,22,24,25,28}$ & 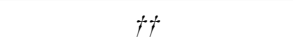 & $0(0.06-12.6)^{15,30}$ \\
\hline
\end{tabular}

Values shown are confidence intervals.

Note: All incidence rates for adverse events are calculated based on the entire time period for which patients were followed in the study. However, some studies may have identified specific adverse events earlier than their reported patient follow-up. These studies are identified in the footnotes that follow.

CV/pulm, Cardiovascular/pulmonary.

DiPrima et al ${ }^{20}$ study divided patients into 2 groups for follow up.

Nelson et al ${ }^{27}$ study also reported adverse event data for $\leq 7$ days after colonoscopy.

$*^{*}$ Three studies with longer patient follow-up times had data recorded on the day of the procedure with respect to perforation (1.5; 95\% CI, 0.2$5.3)^{20,23,26}$

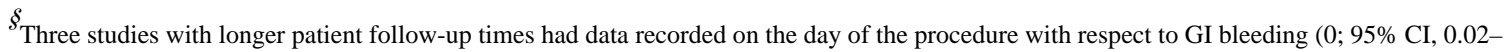
4.1). $20,23,26$

"Three studies with longer patient follow-up times had data recorded on the day of the procedure with respect to CV/pulmonary complications $(10.2 ; 95 \%$ CI, 5.6-17.1). $20,23,26$

II Three studies with longer patient follow-up times had data recorded on the day of the procedure with respect to mortality ( $0 ; 95 \%$ CI, 0.02 4.1). $20,23,26$

${ }^{\#}$ Sardinha et al ${ }^{15}$ study also reported adverse event data on the day of colonoscopy.

** Ko et al ${ }^{30}$ study also reported adverse event data for $\leq 7$ days after colonoscopy.

${ }^{\dagger}$ No data available.

$\mathcal{S}$ Data only available from 1 study. 